\section{EPS - A New Conference Policy}

As for many other Learned Societies, one of the roles of EPS consists in organising conferences. Not only do our Divisions, some of their Sections, and Interdivisional Groups have General Meetings, with a repetition rate which varies from one to another, but many of these groups, as well as some of our Committees, also organise small Workshops, Schools or Seminars. That is, one shot events, in general on some "hot" topic which requires the rapid launching of a small but active meeting, or the training of young (or less young) researchers. These activities are promoted under the scientific responsibility of the corresponding Board, they are "endorsed" by EPS.

As far as conferences are concerned, our Society has decided, since its foundation, to take in charge another, broader, responsibility with respect to the community of European physicists. That is, it sponsors conferences. This means that the conference organisers have asked the Society to judge the quality and also the European character of their future conference, and that our judgement has been favourable. During the cold war, this sponsorship was an important help for some potential participants to obtain their visas and attend such meetings taking place out of their home country. But times have changed and the iron curtain has been transmuted into a golden curtain. For many physicists living in countries lacking hard currencies, travel and living expenses are now, frequently, the main barrier preventing them from attending even those meetings which are most fundamental for the building of an active physics community in their own country. Also, in the present time of shrinkage of science budgets in many European countries, it becomes more and more difficult for a conference organiser to raise the funds necessary for the venue of a conference, and at the same time dispose of some scholarships for helping deserving cases.

Yet, a Society as ours has the capacity of judging, in each given subfield of physics, which are the most promising conferences among the large number of meetings organised each year. Pointing out to the funding agencies those which are, in our judgement, the most promising conferences is the challenge that the Action Committee on Conferences has accepted. But we are also conscious of the fact that the more we are involved in the consequences of our judgements, the more serious they will appear to the rest of the community and the larger may become their impact. EPS has therefore decided to enforce the following policy :

a) to raise the standards for the "sponsored" events, so that EPS sponsorship really represents a seal of high quality.

b) to offer to the corresponding conference organisers, or, at least to some of them, a few scholarships to help some young participants from evolving countries take part in these events.

As before, the quality judgement will be made by the Action Committee, in which all the EPS Divisions and Interdivisional Groups are represented. This Committee also administers the Solidarity Fund which allocates those scholarships. Because of the limited resources of this Solidarity Fund, the Committee has decided that it will focus its efforts on those events where the result would be most effective, that is, small Workshops or Schools where the specialisation on a given topic guarantees each participant the opportunity of meeting many of the major actors in the field, to build up relationships with other groups working on similar subjects, and to learn about the newest developments. For the same reason, the Solidarity Fund will favour events attended by the most active researchers. This policy of the Solidarity Fund already applies to "endorsed" conferences, one part of the new policy we are creating is to extend it to the "sponsored" events.

This new policy is made possible by the contributions of the Divisions and Interdivisional Groups and through the help of the National Societies in strengthening the financial position of EPS. We expect it will help to increase the role of our Society in the organisation of the European physics community to the benefit of all of its members.

The EPS Solidarity Fund was created in 1994 on the initiative of EPS Divisions. "Endorsed" conferences include a contribution to the Solidarity Fund in their conference fee, whereas EPS adds a yearly contribution from its central budget. Sponsored conferences are not asked for contributions, but any donation from, e.g. an unexpected surplus, is highly welcome.

For further information, please contact: The Secretary General

European Physical Society

34 rue Marc Seguin

F-68060 Mulhouse, France

Fax: +33389329449

E-mail:j.williams@univ-mulhouse.fr



\section{European Physical Society}

Published by Europhysics News to inform members. Editor: C.C.J. Schneider, EPS, 34 rue Marc Seguin, F-68060 Mulhouse Tel +33-389329444-Fax +33-389329449

\section{First EUPEN General Forum}

\section{August 29-30, 1997Natienhuis Grand} Hotel Oude Burg, Brugge, Belgium

The first EUPEN General Forum is a two-day gathering where not only the EUPEN contact persons and their colleagues, but all staff members and students from Physics Departments, plus secondary school teachers, from all over Europe, are invited to discuss the EUPEN thematic project in the SOCRATES framework. The main aim is to establish contact between people and groups of persons, which have to offer each other an added value in the field of Physics Education and Mobility in Europe.

Organised by the EUPEN Consortium with the help of the SOCRATES TNPs programme of DG XXII, the Forum on Education and the University Teaching Section in the IDGPE (Interdivisional Group Physics Education) of the EPS (European Physical Society), the Arbeitskreis Optionen für die Zukunft der DPG (Deutsche Physikalische Gesellschaft) and the Universiteit Gent.

\section{Organising Committee}

F. Brut (Grenoble, FR), E. Cunningham (Dublin, IE), L. Dona dalle Rose (Padova, IT), J. Dore (Canterbury, GB), H. Ferdinande (chair, Gent, BE), C. Ferreira (Lisboa, PT), J.-P. Hansen (Bergen, NO), G. Jones (London, GB), A. Konsta (Athina, GR), S. Kubsky (Bochum, DE), R. Pinto (Barcelona, ES), J.-Cl. Rivoal (Paris, FR), P. Sauer (Hannover, DE), I. Sosnowska (Warszawa, PL), G. Tibell (Uppsala, SE), M. Vicentini (Roma, IT)

\section{Local Organizing Committee}

A. Petit, H. Ferdinande (Gent, BE)

For further information and registration details, please contact:

First EUPEN General Forum c/o Anne Petit, Universiteit Gent, Proeftuinstraat 86

B- 9000 Gent, Belgium

Tel: +3292646539

Fax: +3292646699

E-mail:anne.petit@rug.ac.be 


\section{Venue}

The Forum will be held in the Natienhuis Grand Hotel Oude Burg, Oude Burg 5, B-80oo Brugge, Belgium Tel: +3250445111, Fax: +32504451 oo

\section{Programme}

The programme will include a general interest opening talk, plenary presentation of the results of the EUPEN Questionnaires (prepared to document information on the teaching of physics throughout Europe) by the Chairpersons and Secretaries of the Executive Groups, parallel discussions of the Working Groups, conclusions and outlook for the consortium.

\section{Fees}

- Staff members and research students of EUPEN member institutions: $100 \mathrm{ECU}$ if registration is completed before 30 June, 1997, and 150 ECU if registration is completed after this date

- Staff members of non-member institutions: $200 \mathrm{ECU}$ if registration is completed before 30 June, 1997, and 300 ECU if registration is completed after this date

- Secondary school teachers: 50 ECU if registration is completed before 30 June, 1997 , and $75 \mathrm{ECU}$ if registration is completed after this date

- First-degree students (To be eligible for the student registration fee, participants must submit proof of firstdegree student status): 25 ECU if registration is completed before 30 June, 1997 , and $40 \mathrm{ECU}$ if registration is completed after this date

Coffee/tea breaks during morning and afternoon sessions, plus two lunches and one dinner, are included. All fees may be paid in ECU or BEF, by bank transfer or postal transfer (cheaper) or by International Postal Money Order to: Name of the financial institution: De Post, 1100 Brussel, Belgie Account number: $000-1718140-76$ Account name: Anne Petit, Universiteit Gent, Proeftuinstraat 86, B-90oo Gent, Belgium

\section{Accommodation}

Hotel accommodation is the responsibility of the participant. However, a number of rooms has been blocked at the Grand Hotel Oude Burg for Forum participants and guests until Sunday 31 May 1997.

Single room: $2950 \mathrm{BEF}$ (incl. breakfast) Double room: $3750 \mathrm{BEF}$ (incl. breakfast) Grand Hotel Oude Burg Oude Burg 5, B-800o Brugge, Belgium.
Hotel contact person: Mrs Inge Laridon.

Reference number for bookings: 21527 . Reservations only take effect upon receipt of payment.

Other accommodation possibilities are available on the WWW at: http://www.brugge.be/toerisme/hotels.htm

A hotel booking form is available on the WWW at:

http://www.brugge.be/toerisme/boekfrm.htm, or may be obtained by contacting the EUPEN Secretariat at the above address.

Updated information concerning the Forum can also be obtained on the WWW at: http://allserv.rug.ac.be/ hferdin/eupen/forum/

At the end of March, 1997, the EUPEN Secretariat submitted a renewal application for the future funding of EUPEN by SOCRATES. It is to be noted that the International Association of Physics Students (IAPS) has recently joined in the work of EUPEN. More information about the IAPS can be obtained from:

International Association of Physics Students, Sala de Alumnos, Facultad de Ciencias, Universidad Granada, 18071 Granada, Spain Tel: +3458243370, Fax: +3458246387 E-mail: iaps@nikhef.nl http://www.nikhef.nl/pub/iaps/

\section{Membership of EPS Divisions and Interdivisional Groups of the European Physical Society}

We encourage members of National

Physical Societies to register as members of the Divisions and Interdivisional Groups of EPS. Registration may be accomplished by using the following "form" which may be returned to the Mulhouse secretariat:

Name:

First name:

National Society:

Mailing address (private or institute):

Institute name:

PO Box, or street and number:

City:

Country:

Please place an X next to the Division(s) or Interdivisional Group(s) you wish to join: Name

Abbreviation

Astrophysics Division:

ASX

- Solar Physics Section

ASSO

Atomic and Molecular

Physics Division:

- Atomic Spectroscopy Section

APXX

- Chemical Physics Section
- Electronic and Atomic Collisions Section

APEL

- Molecular Physics Section

APMO

Condensed Matter Division:

- Liquids Section

CMLI

- Low Temp. Physics Section

CMLO

- Macromolecular Physics Section CMMA

- Magnetism Section

CMMG

- Metals Section

CMME

- Semiconductors and Insulators Section

- Surfaces and Interfaces Section CMSU

High Energy and Particle Physics Division

HIXX

Nuclear Physics Division NUXX

Plasma Physics Division PLXX

Quantum Electronics and Optics Division

QUXX

Accelerators Interdivisional Group ACXX Applied Physics and Physics in Industry

Interdivisional Group

PIXX

Computational Physics

Interdivisional Group

Experimental Physics Control Systems

Interdivisional Group

CPXX

History of Physics

Interdivisional Group

EXXX

Physics Education Interdivisional Group

PEXX

Physics for Development

Interdivisional Group

Date (day/month/year):

Alternatively, this form may be obtained by contacting: epsbud@sunserv.kfki.hu (after completion, it may be returned to the same E-mail address for processing). It is important that the Members of the National Physical Societies who wish to take advantage of this offer give their names, as this is the only way in which we can check to see if they are actually Members of a National Physical Society and therefore have a right to apply for membership of an EPS Division or Interdivisional Group. However, we sincerely hope that this appeal, and regular appeals of a similar nature, will encourage as many Members of National Physical Societies as possible to take an interest in the work of the Divisions and Interdivisional Groups of EPS. And in this way contribute to further the aims and objectives of the EPS.

Jeffrey Williams

Dr. J. Williams has decided not to become Secretary General and will leave the Society on August 31. The present Secretary General has agreed to continue until a new appointment is made. A new Editor, Tobias Chapman has been appointed from June 1, 1997.

Further details will appear in the next issue. 